Formation of alkali labile linkages in DNA by hedamycin and use of hedamycin as a probe of protein-DNA complexes

George N.Bennett

Department of Biochemistry, Rice University, Houston, TX 77001, USA

Received 27 April 1982; Revised and Accepted 24 June 1982

\begin{abstract}
Hedamycin forms a stable complex with DNA and introduces alkall labile linkages in the DNA. These labile linkages are located at deoxyguanosine residues and are cleaved by the treatment used for breakage at bases alkylated by dimethyl sulfate. The reaction of hedamycin with all $G$ residues in the chain is not uniform, and certain positions, particularily those in TG tracts, are especially reactive. The reaction of hedamycin with DNA can be inhibited by ethidium bromide, suggesting that intercalation is important in positioning the reactive group of hedamycin near to the base which is modified. The low amount of hedamycin needed to produce observable breakage, its specificity for reaction with DNA and its ability to react with DNA under mild conditions make it suitable for use as a probe of protein-DNA complexes. This was shown by the ability of lac repressor and RNA polymerase to block reaction of hedamycin with the DNA of the lac regulatory region.
\end{abstract}

\title{
INTRODUCTION
}

Hedamycin is an antibiotic isolated from Streptomyces griseoruber C-1150 (1) and is similar in structure to kidamycin (2) in that it contains two amino-sugar substituents attached to an anthraquinone chromo-

phore (3). Hedamycin also contains a reactive diepoxide moiety not present in kidamycin. Recent $\mathrm{nmr}$ (4) and crystallographic studies (5) have allowed the complete structure and conformation of hedamycin to be established (Fig. 1).

The hedamycin chromophore is structurally related to that of the anthracycline antibiotics adriamycin and daunomycin $(6,7)$. The interaction of daunomycin with DNA has been studied in some detall. It forms a rather stable complex with DNA and models of the complex have been proposed $(8,9,10)$ which include intercalation of the ring system and place the amino sugar group in the major groove of the DNA hel1x. Recent studies of various anthracycline antibiotics have revealed structural features important in DNA binding (11) and for in vivo activity (12). Anthracycline derivatives have been reported to react with native DNA to 


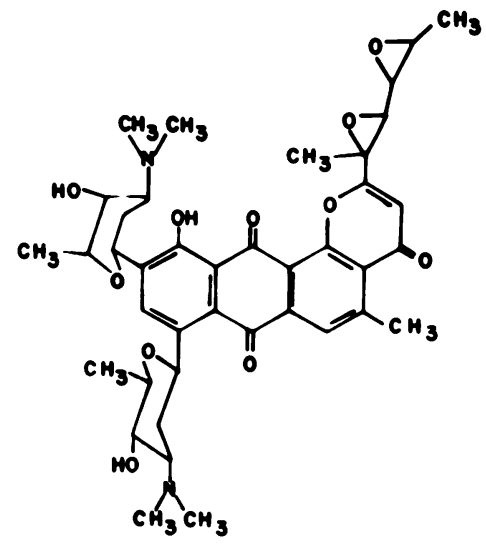

\section{HEDAM YCIN}

Figure 1. The covalent structure of hedamycin as determined by Sequin et a1. $(2,4,5)$. The diagram is not meant to represent the exact conformation or configuration (see 5 ).

form covalent adducts in a photo activated process $(13,14)$.

Hedamycin has been reported to be inhibitory on the growth of microorganisms, HeLa cells and transplanted tumors, Induces E. coll $\lambda$ lysogens and is a potent antiphage agent (15). These toxic effects probably derive from its ability to bind DNA and to inhibit nucleic acid synthesis (16). A complex between hedamycin and DNA cannot be dissociated by extensive dialysis or cesium chloride gradient centrifugation $(16,17)$. Upon binding DNA, a shift in the absorbance spectrum of hedamycin is observed concomitant with an increase in the $T m$ of the DNA and a decrease in the density at which the DNA bands in cesium chloride gradients. Jernigan et al. (17) proposed that the planar ring system of hedamycin might intercalate and then the non-dissociable complex form by covalent attachment of hedamycin to the DNA via alkylation of DNA bases by the epoxide group. It had also been suggested that the DNA breakage observed in alkaline sucrose gradients was due to alkali labile damage induced by treatment with hedamycin (18).

In order to obtain more information about the reaction of hedamycin with DNA, in vitro experiments with uniquely end-labeled DNA fragments were performed. Studies of this type have been used to Identify the position of action of various nucleases and DNA modifying agents $(18,19)$. 
These experiments revealed the production of alkali labile modifications at deoxyguanosine residues upon reaction with hedamycin, and suggest that certain deoxyguanosines in the chain are preferred sites of reaction. The reaction is rapid and is carried out under mild conditions; therefore it is suitable for use as a specific probe of protein-DNA complexes.

METHODS

Hedamycin was obtained from Dr. W. Bradner, Bristol Laboratories, Syracuse, N.Y. A solution of hedamycin $\left(\varepsilon_{428 \mathrm{~nm}}=10000\right)(0.25 \mathrm{mM})$ in 1 mM sodium phosphate, $0.1 \mathrm{mM}$ EDTA, $\mathrm{pH} 6.0$ was stored in the dark at $4^{\circ}$. It has been reported that hedamycin is fully active after three months when stored under these conditions (16). Aliquots were removed and diluted to $5 \mu \mathrm{M}$ in the above buffer for daily use.

Restriction enzymes, RNA polymerase, polyacrylamide gels, and DNA isolation procedures were as described previously (21). BspRI - EcoRI fragments containing the lac regulatory region were isolated from pLA322-8 and pLA322-12 (Dr. J. Sninsky, personal communication) and labeled with $\alpha-{ }^{32}$ P-dATP and DNA polymerase as described (22). Dimethyl sulfate, hydrazine and piperidine reactions were performed as described (22). 7M urea polyacrylamide gels were prepared and electrophoresis performed as described (23).

Routine hedamycin experiments were carried out as follows. A 100 $\mu 1$ reaction mixture was prepared. It was composed of a solution of 10 $\mathrm{mM}$ HEPES $\mathrm{pH} 7.4,10 \mathrm{mM} \mathrm{MgCl}_{2}, 100 \mathrm{mM} \mathrm{KCl}, 0.1 \mathrm{mM}$ EDTA, $1 \mathrm{mM}$ dithiothreitol, and $50 \mu \mathrm{g} / \mathrm{ml}$ bovine serum albumin and it also contained $0.3 \mu \mathrm{g}$ unlabeled pBR322 DNA and 0.1 pmol of the labeled DNA fragment (see Fig. 2). The small amount of labeled DNA (about 0.1 pmole of 100 bp fragment) in the reaction mixture allowed the particular positions of alkali labile bonds to be observed after separation of the cleaved DNA by polyacrylamide gel electrophoresis and autoradiography as in a DNA sequencing procedure $(22,23)$. The larger quantity of unlabeled DNA (about 0.12 pmole of plasmid DNA or approximately 5 pmoles of 100 bp long DNA) allowed the ratio of hedamycin to total DNA nucleotides to be adjusted more easily and reproducibly. To this reaction mixture the protein used In protection experiments ( $6 \mu \mathrm{g}$ lac repressor or $3 \mu \mathrm{g}$ RNA polymerase) was added in a volume of a few microliters. After a ten minute preincubation at $37^{\circ}, 4 \mu 1$ of $5 \mu \mathrm{M}$ hedamycin in $1 \mathrm{mM}$ sodium phosphate, $\mathrm{pH} 6.0$, 
$0.1 \mathrm{mM}$ EDTA was added. The reaction with hedamycin was allowed to continue for 10 minutes at room temperature, then an aliquot of sonicated salmon sperm DNA ( $15 \mu 1$ of a $1 \mathrm{mg} / \mathrm{ml}$ stock), and a sodium acetate solution $(140 \mu 1$ of $0.75 \mathrm{M}$ containing $50 \mu \mathrm{g} / \mathrm{ml}$ tRNA) were added. The DNA was precipitated by addition of ethanol $(0.7 \mathrm{ml})$. The sample was frozen at $-70^{\circ}$ for several minutes before centrifugation for $5 \mathrm{~min}$ in an Eppendorf centrifuge. The precipitate was resuspended in $0.3 \mathrm{M}$ sodium acetate, reprecipitated with ethanol and washed with ethanol before dryIng. The hedamycin reacted DNA was cleaved with $1 \mathrm{M}$ piperidine at $95^{\circ}$ for $40 \mathrm{~min}$ in the same way that dimethyl sulfate and hydrazine reactions were worked up in the Maxam-Gilbert DNA sequencing technique (23).

RESULTS

Reaction of hedamycin at deoxyguanosine residues

A singly end-labeled fragment (see Figure 2) was incubated with a high concentration of hedamycin under conditions which should nearly saturate the DNA with hedamycin (17). The reacted product was subjected to electrophoresis on denaturing gels to see if any cleavage had occured in the DNA due to the hedamycin treatment (Fig. 3). A small amount of cleavage was observed (lane 5). The sample was also treated with acid and alkali to see if susceptible linkages had been introduced. When the hedamycin-treated DNA was treated with alkal1, substantial degradation of the DNA was observed (lane 4). The position of the dark bands caused by DNA breakage corresponded to those found upon alkylation with dimethyl sulfate (lane 1). Much of the DNA was cleaved at the $G$ nearest the labeled end with most of the remainder cleaved at other G residues. No additional acid labile cleavages were observed under conditions which would have been expected to cleave at N-3 alkylated deoxyadenosine (lane 6). When the exposure to acid was included (lane 6) the same cleavage pattern was observed as with just an alkall treatment (lane 4). The major reaction of hedamycin which results in alkali labile linkage occurs at deoxyguanosine positions of the DNA chain. It is 11kely that this occurs through alkylation of the $N-7$ position of deoxyguanosine although other possibilities for this reaction cannot be eliminated. Preference of hedamycin for reaction at certain deoxyguanosine residues

The band intensities at various deoxyguanosines in the DNA chain show a more pronounced variation in the hedamycin reaction (Fig. 4, lanes 2 and 4) than is observed for alkylation by dimethyl sulfate (Fig. 


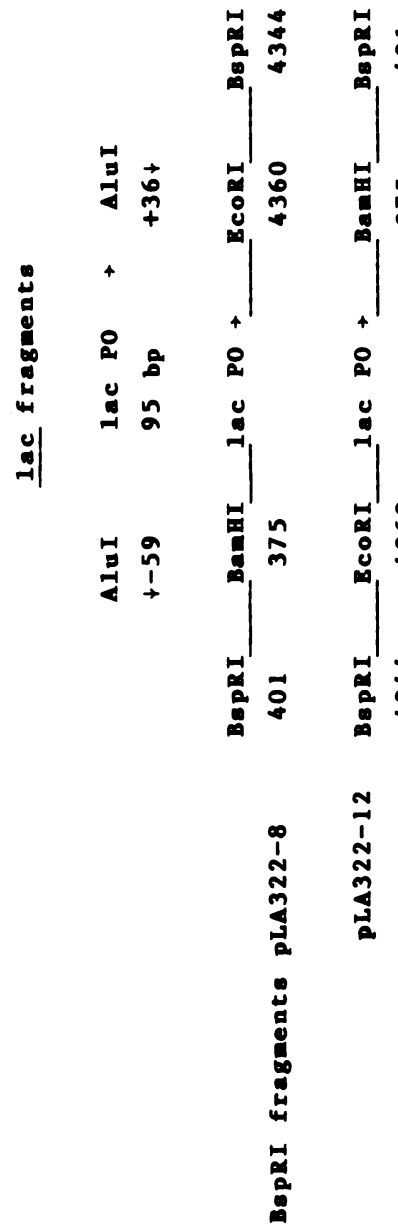

$$
\text { 운- }
$$$$
4
$$$$
\text { H } 4
$$$$
\text { (c) } 0
$$$$
00
$$$$
\text { H } 4
$$$$
\text { (c) }
$$$$
\text { (1) } 0
$$$$
\text { (6) } 0
$$$$
\text { 咅 }-00
$$$$
\rightarrow 4
$$$$
\text { H } 4
$$$$
00
$$$$
\text { c) } 0
$$$$
\text { H4 }
$$$$
4+
$$$$
\text { H } 4
$$$$
+4
$$$$
M<
$$$$
\text { i - }
$$$$
41
$$$$
00
$$$$
4 H
$$$$
+4
$$$$
H<
$$$$
\text { H } 4
$$$$
00
$$$$
\text { (1) } 0
$$$$
000
$$$$
\text { i }-41
$$$$
\text { ( }
$$$$
0
$$$$
0 \text { c }
$$$$
\text { ( ) }
$$$$
4 \mu
$$$$
00
$$$$
\text { c) } 0
$$$$
\text { c) } 0
$$$$
\text { กิ-4 } 4
$$$$
41
$$$$
00
$$$$
\text { H } 4
$$$$
\text { บ } 0
$$$$
4 \mathrm{H}
$$$$
00
$$$$
\text { în }
$$

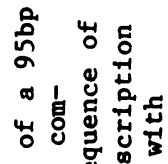

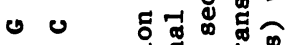

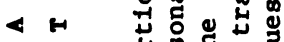

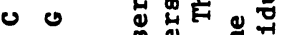

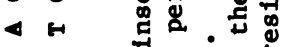

- H

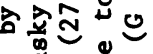

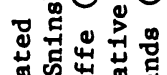
ڤึ こ出 品苛点

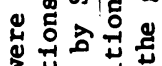

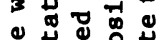
岕莒莒 运造造出 둥

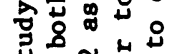
ป ป ญ

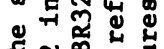
ป N

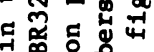
劉。首的

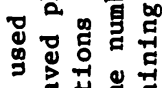
密出蛋 㫕 攵 品

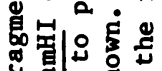

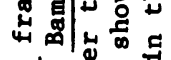

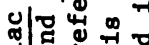
枂 \& 거용 ฟ 岁四|更造 눌영 岂岂芯芯 岂苔总 出息 宣 事步 至出首岕 ^

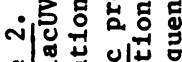
ఖ

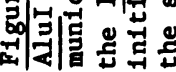




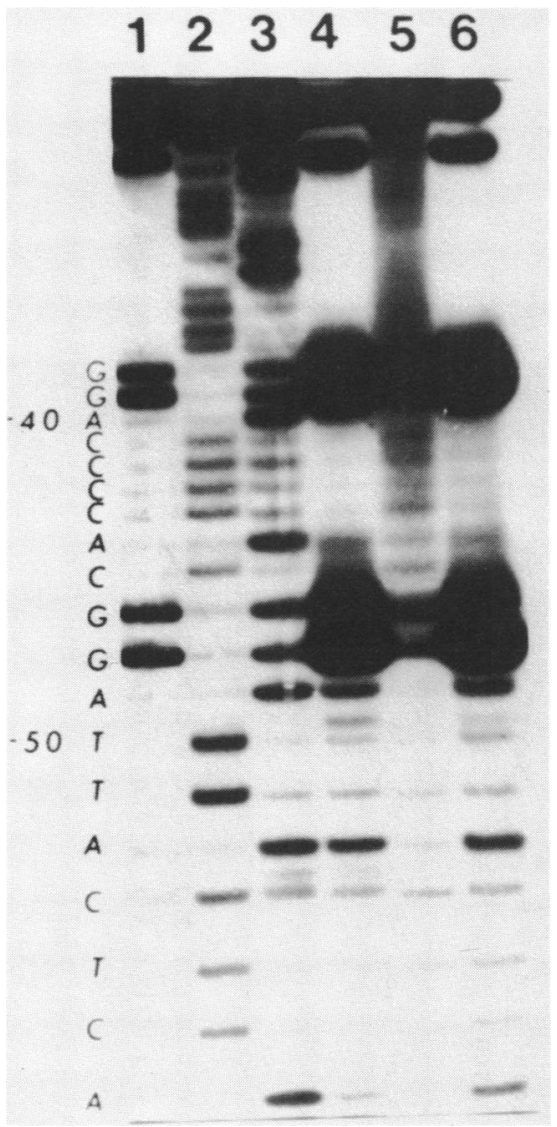

Figure 3. Reaction of hedamycin with DNA. A $5^{\prime}$ end labeled DNA fragment containing the lac EcoRI-HpaII segment of pLA322-8 (Figure 2) was used. The sequence corresponds to the upper strand from -56 to -38 and Is shown along side the gel lanes. (lane 1) Dimethyl sulfate reaction followed by piperidine cleavage; (lane 2) Hydrazine $C+T$ reaction followed by piperidine cleavage; (lane 3) Piperidine formate A+G reaction followed by piperidine cleavage; (lane 4) Reaction with hedamycin ( $5 \mu \mathrm{g} / \mathrm{ml}$ In $1 \mathrm{mM}$ sodium phosphate, $0.1 \mathrm{mM}$ EDTA, $\mathrm{pH} 6.0$ ) for $2 \mathrm{hr}, 25^{\circ}$ followed by piperidine cleavage; (lane 5) Hedamycin reaction as in lane 4 without piperidine workup; (lane 6) Hedamycin reaction as in lane 4 followed by piperidine formate treatment and piperidine cleavage.

4, lanes 1 and 3). The most reactive deoxyguanosines in the chain (Fig. 4, lane 2) are those which have an adjacent $5^{\prime}$ thymidine (TG sequence). Those with 5'-deoxyadenosine (AG sequence) are generally less reactive and in the case of runs of deoxyguanosines, the second and subsequent deoxyguanosines (NGGG sequence) from the $5^{\prime}$ end of the tract are almost 


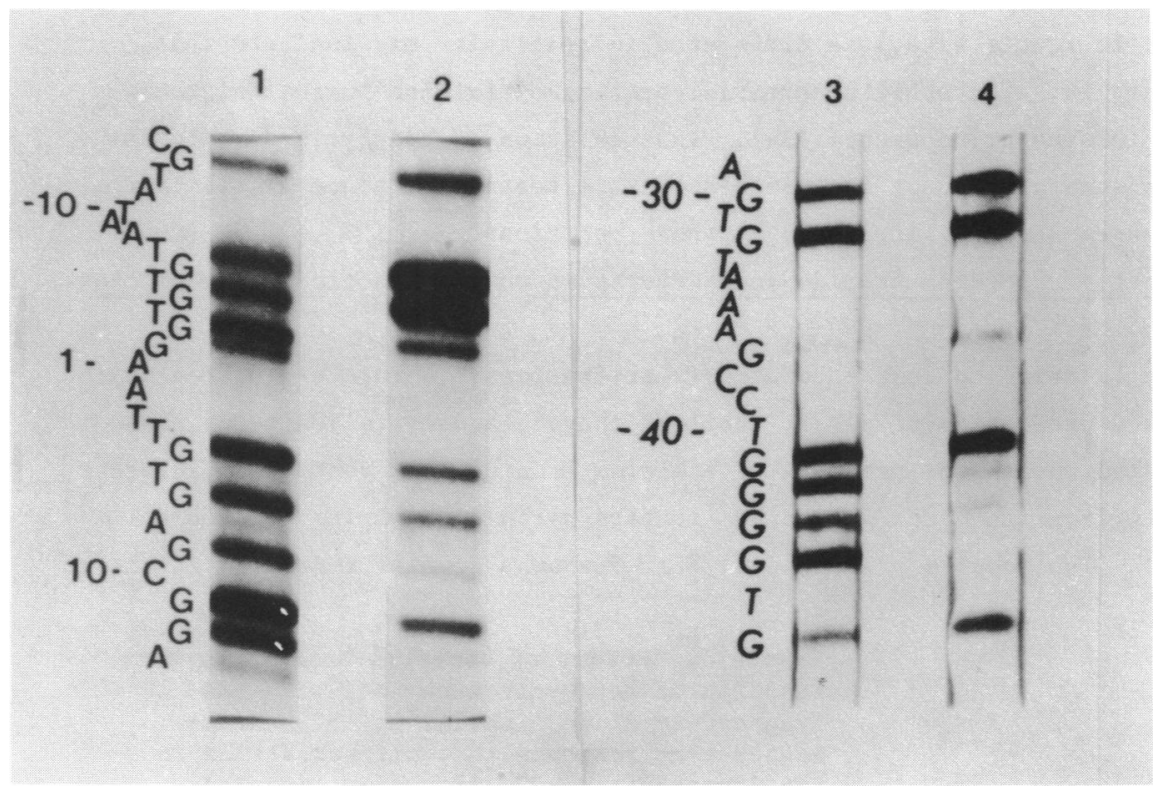

Figure 4. Preferential reaction of hedamycin at certain G residues. DNA fragmengţs (EcoRI-BspRI) spanning the lac region (F1g. 2) were labe1ed with $\alpha^{-32} \mathrm{P}-\mathrm{d} \overline{\mathrm{ATP}}$ at the $3^{\prime}-\mathrm{EcoRI}$ end. The fragments were subjected to reaction with dimethyl sulfate or hedamycin under the minimal reaction conditions described in Methods. (lane 1) The fragment was labeled at the $3^{\prime}$ end (+36, upper strand, Fig. 2) and reacted with dimethyl sulfate followed by cleavage with piperidine; (lane 2) The fragment reacted with hedamycin and cleaved with piperidine; (lanes 3 and 4) The fragment was labeled at the $3^{\prime}$ end at -62 , the sequence corresponds to the bottom strand of diagram in Fig. 2, (lane 3) Reaction with dimethyl sulfate then piperidine cleavage; (lane 4) Hedamycin reaction and piperidine cleavage on the same fragment used in lane 3.

completely unreacted (Fig. 4, lane 4). These same preferences for the 5' adjacent nucleotide are observed in other DNA fragments which have been examined. The darkest cleavage bands produced by hedamycin action are almost always at TG sequences. However, not all TG sequences have the same high reactivity (F1g. 4, lane 2), certain TGs are only a little more reactive than particular AG or CGs but there are TG tracts which are very reactive. Notice the very intense bands in the TGTGTG area of the gel (lane 2). To explain this feature, sequence effects from more than just the adjacent base may need to be considered.

Since the preference for reaction at TG may result from the rela- 
tive ability of hedamycin to intercalate adjacent to the deoxyguanosines that it reacts with, the difference in reactivity may indicate that hedamycin, like ethidium bromide, prefers pyrimidine-purine neighbors for Intercalation events (24). Intercalation of hedamycin next to deoxyadenosines cannot be examined by this technique, since alkall labile linkages are not introduced at those positions. Effect of Ethidium Bromide and Temperature on the Reaction of Hedamycin with DNA

In order to look more closely at the possible role of intercalation in the production of alkali labile linkages, hedamycin reactions were carried out in the presence of ethidium bromide, an agent which intercalates from the minor groove and prefers pyrimidine-purine neighbors (24). The results presented in Fig. 5 show a drastic reduction in the

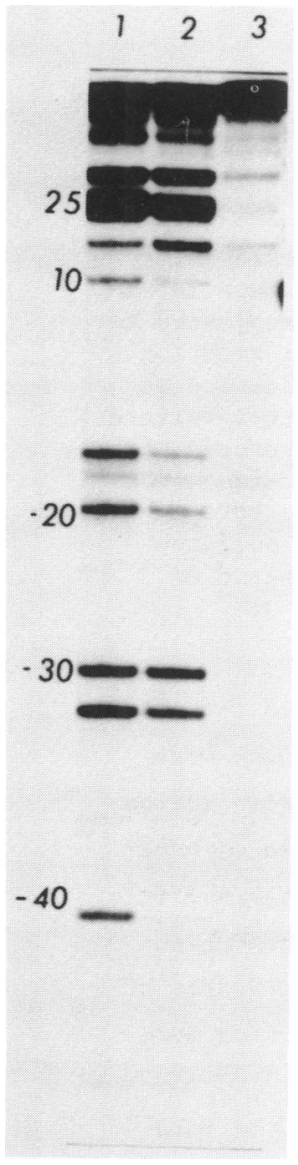

Figure 5. Effect of ethidium bromide on the reaction of hedamycin with DNA. The DNA fragment is $3^{\prime}$ end labeled at -62 and the sequence corresponds to the lower strand in the diagram (FIg. 2). Reaction with hedamycin and piperidine cleavage: (lane 1) no ethidium bromide; (lane 2) ethidium bromide $5 \mu \mathrm{g} / \mathrm{ml}$; (lane 3) ethidlum bromide $50 \mu \mathrm{g} / \mathrm{ml}$. 
amount of alkali labile linkages introduced by hedamycin in the presence of ethidium bromide. These concentrations of ethidium bromide did not affect the pattern or extent of modification of deoxyguanosines of the fragment when dimethyl sulfate was used as the alkylating agent. This result suggests that intercalation is an important event in the production of an alkali labile base. In comparing the reaction of hedamycin In the lower concentration ranges of ethidium bromide (lane 2, Fig. 5) with the hedamycin reaction when no ethidium bromide is present (lane 1 ), It is observed that the most intense bands (around +25 ) are more reduced in intensity relative to the TG bands at 34 and 17 . The TG bands at -41 and -32 and the CG bands at -19 and -14 are also substantially reduced compared to their intensities in the no ethidium track (lane 1). The reaction of hedamycin with those deoxyguanosines is inhibited. This result suggests a competition between hedamycin and ethidium bromide for these pyrimidine-purine sequences. The inhibition of the reaction of hedamycin to form alkall labile linkages by ethidium bromide supports the idea of competition between these two agents. This competition had been suggested previously from the observed reduction in ethidium bromide induced fluoresence of DNA which had been treated with hedamycin (18).

The effect of temperature was studied by reaction of the above fragment with hedamycin at temperatures from $4^{\circ}$ to $70^{\circ}$. Little change In the pattern occurred during the change from $20^{\circ}$ to $70^{\circ}$, with either dimethyl sulfate or hedamycin. However at $4^{\circ}$, the extent of the reaction of both agents was substantially reduced relative to the reaction at $20^{\circ}$. The relative intensities of the various bands were not distinctly different, and the very intense bands from the hedamycin reaction retalned their prominence at higher and lower temperatures. Hedamycin as Probe of Protein-DNA Complexes

To examine the feasibility of using hedamycin as a probe in studying protein-DNA interactions, hedamycin reactions were carried out in the presence of proteins which bind to the lac operon fragment. The same experimental protocol as above was used (see Methods). A mixture of the labeled DNA fragment and unlabeled PBR322 DNA was incubated in the presence of RNA polymerase or lac repressor, and after allowing a few minutes for protein binding, a small amount of hedamycin (see Methods, this amount of hedamycin is equivalent to a few molecules of hedamycin per $100 \mathrm{bp}$ of total DNA in the reaction mixture) was added and allowed 
to react for 5-10 min. An excess of carrier DNA and tRNA was then added and the mixture precipitated with ethanol. The DNA was cleaved at labile linkages with piperidine and electrophoresis in a denaturing polyacrylamide gel was carried out. With each of the labeled strands, elimInation of particular bands within the lac operator is observed when the repressor is present during the hedamycin reaction (Fig. 6). A similar

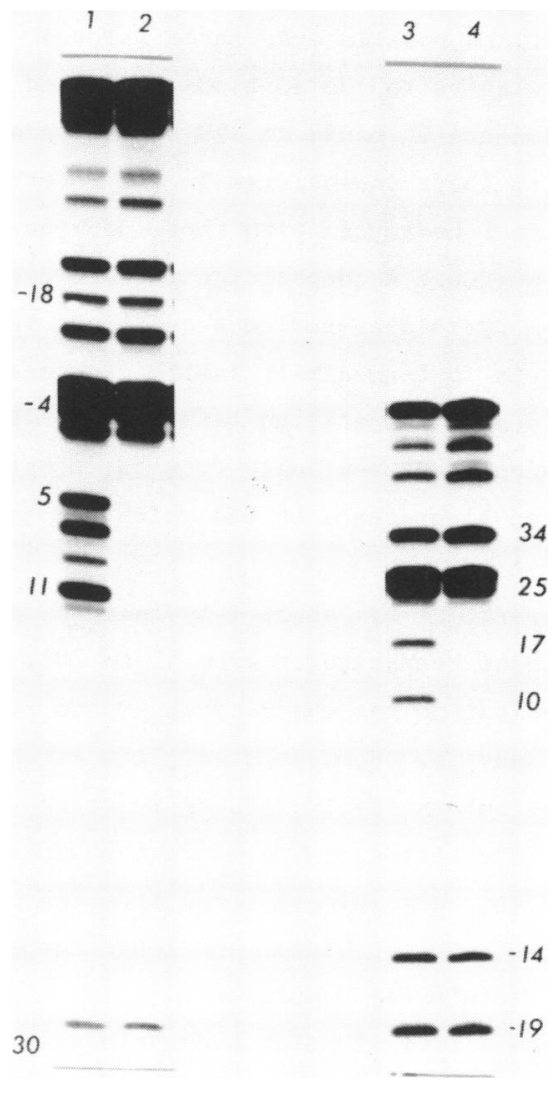

Figure 6. Protection of DNA from reaction with hedamycin by lac repres8or. A BspRI-EcoRI DNA fragment labeled at the $3^{\prime}$ end at +36 was used. The sequence corresponds to the upper strand in the diagram (Fig. 2). The fragment was reacted with hedamycin in the absence of lac repressor (lane 1) or in the presence of $6 \mu \mathrm{g}$ lac repressor protein. Cleavage with piperidine was carried out as before. A EcoRI-BspRI fragment was labeled at the $3^{\prime}$ end at -62 . This sequence corresponds to the lower strand in the diagram (Fig. 2). The labeled DNA was reacted with hedamycin in the absence (lane 3) or presence of $6 \mu \mathrm{g}$ lac repressor (lane 4). 
situation occurs when RNA polymerase is used as the protecting protein (Fig. 7). In this case less complete protection is observed, but a clear reduction in the intensity of deoxyguanosine bands within the normally protected region is observed (25).

\section{DISCUSSION}

The experiments reported here support the mechanism of hedamycin reaction with DNA proposed by Jernigan et al. (17). The reaction produces alkall labile deoxyguanosine residues, and it seems likely that a

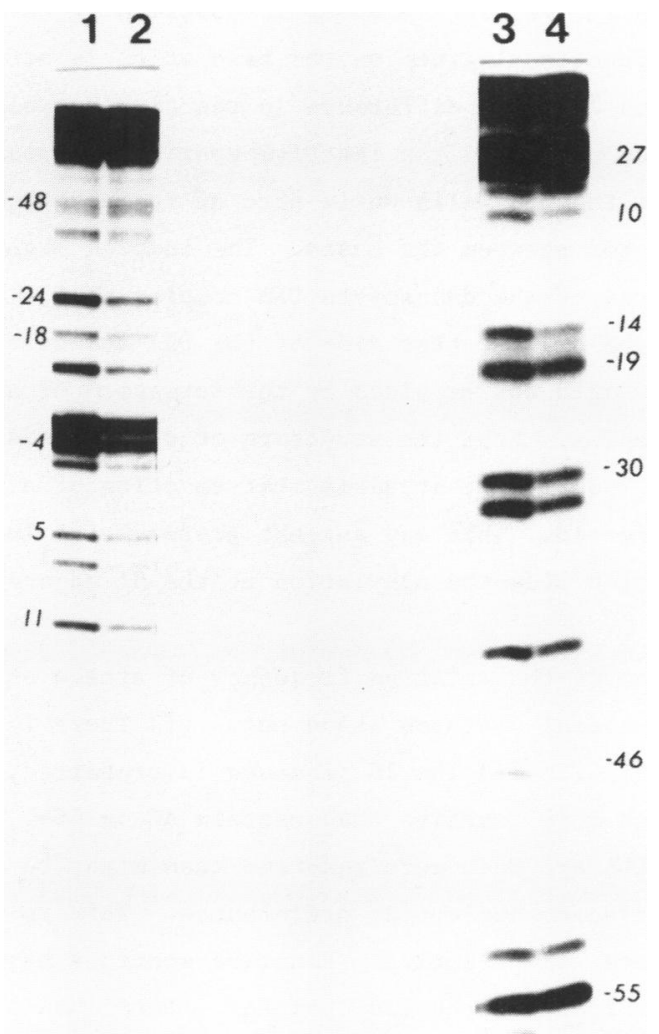

F1gure 7. Protection of DNA from reaction with hedamycin by RNA polymerase. The same fragments as described in Figure 6 were used. Upper strand, reaction in the absence (lane 1) or presence of $3 \mu \mathrm{g}$ RNA polymerase (lane 2); Lower strand, reaction in the absence (lane 3) or presence of $3 \mu \mathrm{g}$ RNA polymerase (lane 4). 
product similar to that produced by other alkylating agents such as dimethyl sulfate is the alkali labile species. These electrophilic agents attack the $\mathrm{N}-7$ position of the guanine ring system to produce a derivative which is very susceptible to imidazole ring opening and subsequent sugar hydrolysis under alkaline conditions. The hedamycin molecule contains the diepoxide group which could generate a reactive species upon opening of an epoxide ring. Examples of alkylation of DNA by epoxide containing compounds are known (26).

The lack of reaction at deoxyadenosines where alkylation of the $\mathrm{N}-3$ position would produce a labile base while reaction at deoxyguanosine procedes fairly easily, suggests a specific positioning of the reactive group near to the functional group on the base which is attacked. A possible explanation for this difference in reactivity would be if the amino glycoside side chain and the reactive epoxide are positioned in the major groove of the DNA helix while part of the anthraquinone ring system is intercalated between the bases. The complex might be somewhat analogous to features of the daunomycin DNA complex $(8,9)$. Since the $\mathrm{N}-$ 3 of adenine would be on the other side of the DNA molecule, any reaction at that point would not be alded by the formation of an intercalated hedamycin complex. From the structure of hedamycin and its relative reaction with TGG vs GGT, it seems that reaction at a sequence of $5^{\prime} \mathrm{T}$ and $3^{\prime} \mathrm{G}$ is preferred. This may suggest preferential intercalation at this sequence which alds the alkylation of the $3^{\prime}$ adjacent deoxyguanosine base.

Upon inspection of the relative frequency of attack at various Gs in the DNA chain, several features stand out. (1) There is little reaction at Gs with a 5' G. (1i) The TG sequence is preferred, although some TG are not much more reactive than certain AG or CGs. (111) Certain areas of the DNA are much more reactive than might be expected, considering only adjacent nucleotide preferences. This is most apparent at some TGs which are very reactive. Reactive sections have been found in the TGTG area surrounding the lac operator. Patel has proposed that this region has an altered DNA structure (23). These reactive positions are inhibited by ethidium bromide competition. This may indicate that certain sites may be significantly more vulnerable to intercalation than others even considering adjacent nucleotide preferences.

The mild conditions needed for reaction (only a few molecules of hedamycin per 100 bp of DNA) and the conditions under which it reacts 
(pHs from 6 to 9 have been used $(16,17,18)$ suggested that it might be a useful agent for probing the structure of DNA around protein-DNA complexes. One such saturation study has been reported with nucleosomes (17). In the experiments in this report, it was shown that bound proteins protected a segment of DNA from attack by hedamycin. More detailed studies may show differences near the protein-DNA boundary regions as conditions are varied. Also, because of its size and the likely involvement of intercalation, it may provide additional information about a protein-DNA complex which is not revealed by the small nonspecific alkylating agent dimethyl sulfate, or by larger enzymatic probes. Its abllity to penetrate bacterial cells and form stable complexes with DNA may also allow it to be used to study DNA accessibility in vivo.

\section{ACKNOWLEDGEMENTS}

I would like to thank Dr. W. Bradner of Bristol Laboratories for the sample of hedamycin, Dr. J. Sninsky for the lac-pBR322 plasmid strains, and Dr. K. Matthews for lac repressor. The research was supported by NIH Grant GM26437 and by the Robert A. Welch Foundation (C820).

\section{REFERENCES}

1. Schmitz, H., Crook, K. E., Jr., and Bush, J. A., (1967) Antimicrob. Agents Chemotherapy-1966, 606-612.

2. Sequin, U., Bedford, C. T., Chung, S. K., and Scott, A. I., (1975) Chemica 29, 527-528.

3. Furukawa, M., Hayakawa, I., Ohta, G., and Iitaka, Y., (1975) Tetrahedron 31, 2989-2995.

4. Sequin, U. and Furukawa, M., (1978) Tetrahedron 34, 3623-3629.

5. Zehnder, M., Sequin, U., and Nadig, H., (1979) Helvectia Chimica Acta 62, 2525-2533.

6. Marco, A., Arcamone, F. and Zunino, F. (1975) in Antibiotics (Corcoran, J.W. and Hahn, F.E., eds.) Vol. III, Springer-Verlag, New York, pp. 101-128.

7. Kersten, H. and Kersten, W. (1974) Molecular Biology and Biophysics 18, Springer-Verlag, New York, pp. 67-86.

8. Pigram, W.J., Fuller, W., and Hamilton, L. D. (1972) Nature New Biology 235, 17-19.

9. Henry, D.w., (1976) in Cancer Chemotherapy, ACS Symposium Series (Sartoll1, A.C., ed.), vol. 30, pp. 15-57.

10. Nuss, M.E., James, T.L., Apple, M.A., and Kollman, P.A., (1980) Bioch1m. Blophys. Acta 609, 136-147.

11. DuVernay, V.H., Jr., Pachter, J.A., and Crooke, S.T. (1979) Mol. Pharmacol. 16, 623-632.

12. Matsuzawa, Y., Ok1, T., Takeuch1, T., and Umezawa, H. (1981) J. Antibiotics 34, 1596-1607. 
13. Yielding, K.L. and Yielding, L.W. (1980) Ann. N.Y. Acad. Sc1. 346, 368-378.

14. Sinha, B.K. (1980) Chem. Biol. Interact. 30, 67-77.

15. Bradner, W. T., Hernemann, B., and Gourevitch, A., (1967) Antimicrob. Agents Chemotherapy-1966, 613-618.

16. White, H. L. and White, J. R., (1969) Blochemistry 8, 1030-1042.

17. Jernigan, H. M., Jr., Irvin, J. L., and White, J. R., (1978) Biochemistry $17,4232-4239$.

18. Mong, S., Strong, J. E., and Crooke, S. T., (1979) Biochem. Biophys. Res. Commun. 88, 232-243.

19. Brown, N. L. and Smith, M. (1980) in Methods in Enzymology (Gross-

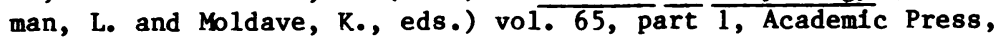
N.Y., Pp. 391-404.

20. Haseltine, W. A., Lindan, C. P., D'Andrea, A. D., and Johnsrud, L., (1980) in Methods in Enzymology (Grossman, L. and Moldave, K. eds.) vol. 65, part 1, Academic Press, N.Y., pp. 235-248.

21. Russe11, D.R. and Bennett, G. N., (1981) Nucleic Acids Res. 9, 2517-2533.

22. Maxam, A. and Gilbert, W., (1980) in Methods in Enzymology (Grossman, L., and Moldave, K., eds.) vol. 65, part 1, Academic Press, New York, pp. 499-560.

23. Maxam, A. and Gilbert, W., (1977) Proc. Nat1. Acad. Sc1. USA 74, 560-564.

24. Pate1, D., (1980) in Nucleic Acid Geometry and Dynamics (Sarma, R., ed.) Pergamon Press, New York, pp. 185-231.

25. Rosenberg, M. and Court, D., (1979) Ann. Rev. Genet. 13, 319-353.

26. Singer, B., (1975) Prog. In Nuc. Acid. Res. and Mol. Biol., vol. 16 , pp. 219-284.

27. Sutcliffe, J. G., (1978) Nuc. Acid. Res. 5, 2721-2728. 